\title{
Kronik Engelli Bireylerde Ortez ve Yardımcı Cihaz Memnuniyetinin Araştırılması
}

\section{Investigation of Orthosis and Assistive Device Satisfaction in Individuals with Chronic Disabilities}

\author{
Tamer Çankaya ${ }^{1 *}$, Alp Özel ${ }^{1}$, Seda Ayaz $\operatorname{Taş}^{2}$, Demet Karabulut ${ }^{3}$, Sezen Tezcan $^{3}$
}

${ }^{1}$ Bolu Abant İzzet Baysal Üniversitesi, Kemal Demir Fizik Tedavi ve Rehabilitasyon Yüksekokulu, Bolu, Türkiye

${ }^{2}$ Özel 75. Y1l Özel Eğitim ve Rehabilitasyon Merkezi, Zonguldak, Türkiye

${ }^{3}$ Özel İlk İlgim Özel Eğitim ve Rehabilitasyon Merkezi, Düzce, Türkiye

e-mail: tamercankaya@hotmail.com,ptalpozel@gmail.com,fzt.seda_ayaz@hotmail.com,

dg_ftr_gozacan@hotmail.com

Orcid:0000-0002-0871-2470

Orcid:0000-0002-1215-7051

Orcid:0000-0002-2778-0065

Orcid:0000-0002-0467-6767

Orcid:0000-0003-4046-9201

*Sorumlu Yazar: Tamer Çankaya

Gönderim Tarihi / Received: 26.12.2018

Kabul Tarihi / Accepted: 17.01.2020

DOI: $10.34087 /$ cbusbed.502872

\begin{abstract}
$\ddot{O} z$
Amaç: $\mathrm{Bu}$ çalışmanın amacı yardımcı cihaz/ortez tavsiye edilen kronik engelli bireylerin ortez kullanım memnuniyetlerinin araştırılmasıdır. Bu çalışmanın bir diğer amacı, tanı grupları ve serebral palsili bireylerin motor fonksiyon seviyeleri ile ortez kullanım memnuniyetleri arasındaki ilişkinin araştırılmasıdır.

Gereç ve Yöntem: Çalışmaya 105 kronik engelli birey (64 serebral palsili, 13 spina bifidalı, 14 musküler distrofili ve 14 farklı nörolojik tanılı birey) ve aileleri dahil edildi. Çalışmaya katılan bireylere yardımcı cihaz/ortez günlük kullanım süreleri ve eğer yardımcı cihaz/ortezlerini kullanmıyorlarsa nedenleri sorgulandı. Bireylerin ortez kullanım memnuniyetleri araştırmacılar tarafından literatüre dayanarak oluşturulmuş Ortez Kullanım Memnuniyet Anketi ile değerlendirildi.

Bulgular: Serebral palsili bireylerin motor fonksiyon düzeyleri ile ortez kullanım memnuniyeti arasında ilişki olmadığı bulundu ( $\mathrm{p}=0.779$ ). Ortez Kullanım Memnuniyet Anketi toplam skoru ve günlük ortez kullanma süreleri arasında pozitif yönlü zayıf bir ilişki saptandı $(\mathrm{r}=0.242, \mathrm{p}=0.015)$. Ortez Kullanım Memnuniyet Anketi toplam skoru ve ne kadar zamandır ortez kullanıldığına ait veriler arasında bir ilişki bulunmadı $(\mathrm{p}=0.811)$. Çalışmaya katılan bireylerin tanılarının $(\mathrm{p}=0.236)$ ve yardımcı cihaz/ortez tipinin ortez kullanma memnuniyeti skorları ile ilişkili

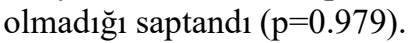

Sonuç: Sonuç olarak, kronik engelli bireylerde yardımcı cihaz/ortez günlük kullanım süresi arttıkça kullanım memnuniyetinin arttığı görüldü. Yardımc1 cihaz/ortez tipinin ortez kullanma memnuniyeti ile ilişkili olmadığ1 gözlemlendi. Ayrıca serebral palsi, spina bifida, musküler distrofi ve diğer tanı gruplarının ortez memnuniyetlerinin benzer olduğu görüldü.
\end{abstract}

Anahtar Kelimeler: Hasta memnuniyeti, ortotik cihazlar, AFO, tekerlekli sandalye.

\section{Abstract}

Objective: The aim of this study was to investigate the orthosis usage satisfaction of chronically disabled individuals who are assisted by the assistive device/orthosis. At the same time, another aim of the study was to investigate whether there is a relationship between the motor function levels and the orthotic use satisfaction of the diagnostic groups and individuals with cerebral palsy. 
Materials and Methods:105 chronically disabled individuals (64 cerebral palsy, 13 spina-bfida, 14 muscular dystrophy, and 14 different neurologic diagnostic individuals) and their families were included in the study. The individuals who participated in the study were questioned about use of assistive device/orthosis, daily use times, and if they did not use assistive device/orthosis, reasons were questioned. Orthotics usage satisfaction was assessed by Orthotics Use Satisfaction Questionnaire, which was based on literature by the researchers.

Results: There was no correlation between motor function levels of individuals with cerebral palsy and orthotic use satisfaction $(\mathrm{p}=0.779)$. There was a weak positive correlation between the total score of Orthotics Use Satisfaction Questionnaire and daily use of orthosis $(r=0.242, \mathrm{p}=0.015)$. There was no correlation between the total score of Orthotics Use Satisfaction Questionnaire and the duration of the use of orthotics $(\mathrm{p}=0.811)$. It was determined that the diagnoses of the individuals participating in the study $(\mathrm{p}=0.236)$ and the assistive device/orthosis type were not related to the orthosis use satisfaction scores $(\mathrm{p}=0.979)$.

Conclusion: As a result, it was observed that assistive device/orthosis increased significantly with increasing daily use. It was observed that assistive device/orthosis type was not associated with orthosis use satisfaction. In addition, cerebral palsy, spina bifida, muscular dystrophy, and other diagnostic groups were found to be similar in orthosis satisfaction.

Keywords: Patient satisfaction, orthotic devices, AFO, wheelchair.

\section{Giriş}

Uluslararası standartlara göre ortezler; nöromuskuler ve iskelet sistemini modifiye etmek amaciyla harici destek olarak kullanılmaktadır [1]. Kasları ve eklemleri desteklemek, kompansatuar mekanizmaları önlemek, fonksiyonel yetersizlikleri azaltmak, günlük yaşam aktivitelerinde bağımsızlığı arttırmak, yürüme yeteneğini geliştirmek, kontraktürleri önlemek, deformitelerin ilerleyişini durdurmak ya da en aza indirmek amacıyla kullanılırlar [1,2]. Kronik engelli bireylerde, yardımcı cihaz ve ortez kullanımı gerek fiziksel fonksiyonların korunması gerekse günlük yaşam aktivitelerinin desteklenmesi açısından rehabilitasyon ekibinin vazgeçilmez unsurlarıdır [3]. Yardımcı cihazların kullanımın, sosyal etkileşim, motivasyon, öz güven, beceri kazanımı (yazı yazma), kognitif beceriler, dikkat süresinin artışı, problem çözme, akademik becerilerde ve üretkenlikte artış gibi birçok olumlu etkileri mevcuttur [4]. Rehabilitasyona yardımcı cihazların değerlendirilmesinde kullanıcı memnuniyeti önemli bir kavramdır ve hasta merkezli yaşam kalitesi çalışmalarında giderek önem kazanmaktadır [3]. Cihazların etkinliği ve kullanıcı memnuniyeti, kanıta dayalı sağlık hizmetlerinde ve kullanıcı odaklı yaklaşımlar için önemli sonuçlar teşkil etmektedir [5]. Engelli bireylerde ortez kullanımının olumlu sonuçlarına rağmen, hastaların yardımcı cihazları kabul etmesi ve kullanması zordur. Cihazın aşırı ağır oluşu, uygulanan bölgeye tam uyumlu olmayışı, giyme ve çıkarma zorlukları, bakıcilar tarafindan yeterince önemsenmemesi gibi şikâyetlerden dolayı engelli bireylerde ortezi kabullenmeme ve memnuniyetsizlik oluşabilir [6]. Çocuklarda ve engelli bireylerde, ortez kulllanımını gerektiren durumlarda ortezin başarısında ailenin rolü oldukça önemlidir [7]. Dolayısıyla yapılan tedavinin amaçları aileye anlatılmalı, ailenin ve çocuğun tedaviyi benimsemesi için çaba gösterilmelidir. Erel ve ark., ortezin görünümünün çocuk hastalar için ortezin Kabullenilmesi ve ortezden memnuniyet açısından önemli olduğunu belirtmiş̧lerdir [8]. Bir diğer çalışmada kullanıcı memnuniyeti ile cihazı hızlı teslim etme, prova etme, güvenirlik arasında olumlu ilişki olduğu bulunmuştur [9].
Literatürde ortez kullanım memnuniyetini değerlendiren çok az sayıda çalışma bulunmaktadır [10]. Son yıllarda ortez ve özel ekipman kullanımı çoğunlukla klinik araştırma ve uygulamalar esnasında yapılmakta ve hem ortopedik hem de nörolojik hastaların fonksiyonel görevler esnasında kişinin fonksiyonel kapasite ve performansını geliştirmek üzere yapıldığı görülmektedir [11]. Bu çalışmanın amacı, yardımcı cihaz/ortez tavsiye edilen kronik engelli bireylerin ortez kullanım memnuniyetlerinin araştırılmasıdır. Bu çalışmanın bir diğer amacı, tanı grupları ve serabral palsili (SP) bireylerin motor monksiyon seviyeleri ile ortez kullanım memnuniyetleri arasındaki ilişkinin araştırılmasıdır. Buna bağlı olarak yardımcı cihaz/ortez kullanım memnuniyetini, süresini, konforunu ve etkisini artıracak çözüm odaklı stratejiler geliştirilmesine yardımcı olmaktır.

\section{Gereç ve Yöntem}

Bu çalışmanın evreni Ereğli, Düzce ve Bolu'daki Özel Eğitim ve Rehabilitasyon Merkezi'ne devam eden ve çalışmaya katılmaya gönüllü $(n=105)$ bireyden oluşturuldu. Çalışma yapılmadan önce Bolu Abant İzzet Baysal Üniversitesi Sosyal Bilimlerde İnsan Araştırmaları Etik Kurulu'ndan 2017/117 no'lu etik kurul izini alındı.

\subsection{Katılımcilar}

Çalışmamıza, yaşları 3-18 yıl arasında SP, spina bifida, musküler distrofi, hidrosefali, otizm gibi problemleri olan ve ayak bileği ortezi (AFO), diz-ayak bileği-ayak ortezi (KAFO), tabanlık, splint veya koltuk değneği, yürüteç, baston gibi yardımcı cihaz kullanan 105 birey ve bu bireylerin ebeveynleri dahil edildi. Herhangi bir cihaz ya da ortez kullanmayan, araştırmayı reddeden bireyler araştırma dişı birakıldı.

Bireylerin ve ailelerinin demografik bilgileri (yaş, cinsiyet, medeni durum, eğitim durumu ve gelir düzeyi gibi) hasta bilgi formu ile sorguland. Yardımc1 cihaz/ortez kullanıp/kullanmadıkları, günlük kullanım süreleri, ne kadar zamandır kullandıkları ve eğer yardımcı cihaz/ortezlerini kullanmıyorlarsa nedenleri 
sorguland1. SP'li 64 bireyin Kaba Motor Fonksiyon Sinıflandırma Sistemi (KMFSS) ile motor fonksiyonları fizyoterapist tarafından değerlendirildi. Ortez kullanım memnuniyeti için literatür taranarak oluşturulan "Ortez Kullanım Memnuniyet Anketi” (OKMA) uygulandı.

\section{2 Ölçekler}

Ortez Kullanım Memnuniyeti Anketi (OKMA): Yazarlar tarafından literatürdeki ilgili makalelerden yararlanarak ortez kullanan bireylerin ortezlerinden ne kadar memnun olduklarını ölçmek için 5'li likert tipinde 10 sorudan oluşan bir anket hazırlandı $[1,6,8,10,12]$. Anket şu soruları içermektedir: 1. Yardımcı cihazın ağırlığından memnun musunuz? 2. Yardımcı cihazın parçalarını ayarlamanın kolay olmasından memnun musunuz? 3. Yardımcı cihazı giyip çıkarma kolaylığından memnun musunuz? 4. Yardımcı cihazın güvenliğinden ne kadar memnunsunuz? 5. Yardımcı cihazın sağlamlığı konusunda ne düşünüyorsunuz? 6. Yardımcı cihazın konforundan memnun musunuz? 7. Yardımcı cihazın tedavideki etkinliğinden memnun musunuz? 8. Yardımc1 cihazın kullanımından memnun musunuz? 9. Yardımcı cihazın cildinize uyumundan memnun musunuz (tahris açısından)? 10. Yardımcı cihazın görüntüsünden (estetiğinden) memnun musunuz? Bireyler her soruya "Hiç memnun değilim" ile "Çok memnunum" arasında 5 seçenekten birini seçerek cevap verdi. Minimum 10, maksimum 50 puan alınan anketten yüksek puan ortez kullanımından memnuniyeti ifade ediyordu. İletişim kurmakta kendi başına yetersiz ve yaşı küçük olan çocukların ebevenyleri tarafindan dolduruldu.

\subsection{Istatistiksel analiz}

Elde edilen verilere ait tanımlayıcı değerler, sayı ve \% frekanslar, ortalama ve standart sapma olarak tablolar halinde verildi. Sayısal özelliklerin normal dağılım gösterip göstermediği Kolmogorov-Smirnov testi ile incelendi. Ortez kullanma süresi ile OKMA(Toplam) değeri arasındaki ilişkiye Pearson Korelasyon Analizi ile bakıldı. Gruplar arası motor fonksiyon seviyeleri, ortez tipleri ve tanılarına göre ortez kullanma memnuniyeti karşılaştırmalarında Kruskal Wallis testi kullanıldı. İstatistik anlamlılık düzeyi olarak $\mathrm{p}<0.05$ alındı ve hesaplamalarda Statistical Package for the Social Sciences (SPSS) versiyon 22.0 programı kullanıldı.

\section{Bulgular ve Tartışma}

Çalışmaya katılan bireylerin yaş ve vücut kitle indeksi (VKİ) ortalaması sirasiyla, $12.18 \pm 7.67$ y1l ve $18.56 \pm 5.35$ $\mathrm{kg} / \mathrm{m} 2$ idi. Bireylerin demografik özellikleri Tablo 1'de gösterildi.

Çalışmaya katılan 105 kronik engelli bireyin \%61'i $(n=64)$ SP, \%12.4'ü $(n=13)$ spina bifida, \%13.3'ü musküler distrofi $(n=14), \% 13.3$ 'ü diğer (hidrosefali, otizm vb.) (n=14) tanılıydı. Ayrıca SP'li bireylerin büyük çoğunluğu (\%48.4) kaba motor fonksiyon seviyesi açısından nonambulatuar düzeydeydi. Sorulara cevap vermek için iletişim kurmakta kendi başına yetersiz ve yaşı küçük olan çocukların 77'sine (\%73.3) annesi, 9'una
(\%8.6) babası ve sadece bir tanesine (\%1.0) ablası yardım etti.

Tablo 1. Çalışmaya katılan bireylerin demografik özellikleri.

\begin{tabular}{|l|c|c|}
\hline & Min-Max & $\mathbf{X} \pm$ SD \\
\hline Yaş (yıl) & $2-35$ & $12.18 \pm 7.67$ \\
\hline Boy uzunluğu (cm.) & $79-177$ & $131.50 \pm 30.28$ \\
\hline Vücut ağırlığı (kg.) & $9.0-90.0$ & $35.02 \pm 20.30$ \\
\hline VKİ (kg/m²) & $7.68-40.00$ & $18.56 \pm 5.35$ \\
\hline
\end{tabular}

Min: minimum, Max: maximum, SD: standart sapma, VKİ: Vücut Kitle İndeksi

18 birey $(\% 17,1)$ sorulara kendisi cevap verdi. Çalışmaya katılan bireylerin 101'inin $(\% 96,2)$ annesi ev hanımıydı. Çallışmaya katılan bireylerin 54'ünün $(\% 51,4)$ babası işçi, 16'sının $(\% 15,2)$ babası emekli, 15'inin $(\% 14,3)$ babası serbest meslekle uğraşıyordu. Ailelerin 64'ünün (\%61,0) 1500-4000 lira, 31'inin (\%29,5) 600-1499 lira yani alt gelir düzeyindeydi. Bireylerin annelerinin eğitim seviyesi 63 kişi $(\% 60,0)$ ilkokul seviyesinde iken babalarının eğitim seviyesi 43 kişi $(\% 41,0)$ ilkokul seviyesindeydi. Çalışmaya katılan bireylerin 94'ünün $(\% 89,5)$ ebeveynleri evliydi. Yardımcı cihaz olarak tekerlekli sandalye, yürüteç ve kanedyen kullandıkları gözlendi. Yardımcı cihaz kullanan bireylerin 28'i ayrıca tekerlekli sandalye kulanıyordu (Tablo 2). Yardımcı cihaz/ortez kullanma süresi ortalama $55.32 \pm 51.67$ ay, günlük kullanma süresi ise $5.22 \pm 4.04$ saat olarak belirlendi. SP'li bireylerin kaba motor fonksiyon seviyeleri Tablo 3'te gösterilmiştir.

Tablo 2. Çalışmaya katılan bireylerin tanıları, yardımcı cihaz ve/veya ortez kullanma durumları.

\begin{tabular}{|l|l|}
\hline Tanı & n (\%) \\
\hline Serebral Palsi & $64(\% 61,0)$ \\
\hline Spina bifida & $13(\% 12,4)$ \\
\hline Muskuler distrofi & $14(\% 13,3)$ \\
\hline Diğer (hidrosefali, otizm vb.) & $14(\% 13,3)$ \\
\hline Yardımcı Cihaz & \\
\hline Tekerlekli sandalye & $28(\% 26,7)$ \\
\hline Walker & $6(\% 5.70)$ \\
\hline Canadian & $2(\% 1.90)$ \\
\hline Ortez & \\
\hline Ayak-ayak bileği ortezi & $59(\% 56,2)$ \\
\hline Kalça-diz-ayak bileği ortezi & $22(\% 21,0)$ \\
\hline Diğer (tabanlık, el spinti vb.) & $13(\% 12,4)$ \\
\hline
\end{tabular}

Tablo 3. SP'li bireylerin kaba motor fonksiyon seviyeleri.

\begin{tabular}{|l|l|}
\hline KMFSS (n=64) & $7(\% 10.9)$ \\
\hline Seviye 1 & $6(\% 9.4)$ \\
\hline Seviye 2 & $11(\% 17.2)$ \\
\hline Seviye 3 & $9(\% 14.1)$ \\
\hline Seviye 4 & $31(\% 48.4)$ \\
\hline Seviye 5
\end{tabular}


Bireyler en çok cihazın giyip çıkarma kolaylığından $(\% 21,9)$, cilde uyumundan $(\% 20)$, görüntüsünden $(\% 19)$ ve konforundan $(\% 16,2)$ memnun değildi. Ortezlerini kullanmama nedenlerinin ise ağrı, vurma, tahriş ve cihazın görüntüsü olduğu bildirildi (Tablo 4).

Tablo 4. Çalışmaya katılan bireylerin OKMA'daki sorulara verdikleri cevapların dağılımları.

\begin{tabular}{|c|c|c|c|c|}
\hline OKMА & $\begin{array}{c}\text { Ayak-ayak bileği } \\
\text { ortezi } \\
\text { n }(\%) \\
\end{array}$ & $\begin{array}{c}\text { Kalça- diz- ayak } \\
\text { bileği ortezi } \\
\text { n }(\%) \\
\end{array}$ & $\begin{array}{l}\text { Diğer } \\
\text { n (\%) }\end{array}$ & $\begin{array}{c}\text { Yardımcı } \\
\text { cihaz } \\
\text { n }(\%) \\
\end{array}$ \\
\hline A ğırlık & $5(8,5 \%)$ & $1(4,5 \%)$ & $1(7,7 \%)$ & $2(9,1 \%)$ \\
\hline Ayarlama kolaylı̆̆ & $7(11,9 \%)$ & $2(9,1 \%)$ & $1(7,7 \%)$ & $1(9,1 \%)$ \\
\hline Giyip çıkarma & $14(23,7 \%)$ & $4(18,2 \%)$ & $4(30,8 \%)$ & $1(9,1 \%)$ \\
\hline Güvenlik & $5(8,5 \%)$ & $2(9,1 \%)$ & - & - \\
\hline Sağlamlık & $3(5,1 \%)$ & $1(4,5 \%)$ & $1(7,7 \%)$ & $1(9,1 \%)$ \\
\hline Konfor & $12(20,3 \%)$ & $4(18,2 \%)$ & $1(7,7 \%)$ & - \\
\hline Etkinlik & $6(10,2 \%)$ & $2(9,1 \%)$ & $1(7,7 \%)$ & $1(9,1 \%)$ \\
\hline Kullanım & $8(13,6 \%)$ & $1(4,5 \%)$ & $1(7,7 \%)$ & - \\
\hline Cilde uyum & $14(23,7 \%)$ & $3(13,6 \%)$ & $3(23,1 \%)$ & $1(9,1 \%)$ \\
\hline Estetik & $11(18,6 \%)$ & $6(27,3 \%)$ & $4(7,7 \%)$ & $2(18,2 \%)$ \\
\hline
\end{tabular}

OKMA: Ortez Kullanım Memnuniyet Anketi

\begin{tabular}{|c|c|c|c|c|c|}
\hline ОКМА & $\begin{array}{l}\text { (1) Hiç } \\
\text { memnun } \\
\text { değilim }\end{array}$ & $\begin{array}{l}\text { (2) Pek } \\
\text { memnun } \\
\text { değilim }\end{array}$ & $\begin{array}{c}\text { (3) Orta } \\
\text { derecede } \\
\text { memnunum }\end{array}$ & $\begin{array}{c}\text { (4) } \\
\text { Oldukça } \\
\text { memnunum }\end{array}$ & $\begin{array}{c}\text { (5) } \\
\text { Çok } \\
\text { memnunum }\end{array}$ \\
\hline & n (\%) & n (\%) & $\mathrm{n}(\%)$ & $\mathrm{n}(\%)$ & $\mathrm{n}(\%)$ \\
\hline $\begin{array}{l}\text { S.1. Yardımcı cihazın ağırlığından } \\
\text { memnun musunuz? }\end{array}$ & $6(5,7 \%)$ & $3(2,9 \%)$ & $35(33,3 \%)$ & $36(34,3 \%)$ & $25(23,8 \%)$ \\
\hline $\begin{array}{l}\text { S.2. Yardımcı cihazın parçalarını } \\
\text { ayarlamanın kolay olmasından } \\
\text { memnun musunuz? }\end{array}$ & $2(1,9 \%)$ & $9(8,6 \%)$ & $29(27,6 \%)$ & $42(40,0 \%)$ & $23(21,9 \%)$ \\
\hline $\begin{array}{l}\text { S.3. Yardımcı cihazı giyip çıkarma } \\
\text { kolaylığından memnun musunuz? }\end{array}$ & $3(2,9 \%)$ & $20(19,0 \%)$ & $22(21,0 \%)$ & $38(36,2)$ & $22(21,0 \%)$ \\
\hline $\begin{array}{l}\text { S.4. Yardımcı cihazın } \\
\text { güvenliğinden ne kadar } \\
\text { memnunsunuz? }\end{array}$ & $0(0,0 \%)$ & $7(6,7 \%)$ & $34(32,4 \%)$ & $44(41,9 \%)$ & $20(19 \%)$ \\
\hline $\begin{array}{l}\text { S.5. Yardımcı cihazın sağlamlığı } \\
\text { konusunda ne düşünüyorsunuz? }\end{array}$ & $0(0,0 \%)$ & $6(5,7 \%)$ & $16(15,2 \%)$ & $49(46,7 \%)$ & $34(32,4 \%)$ \\
\hline $\begin{array}{l}\text { S.6. Yardimcı cihazın konforundan } \\
\text { memnun musunuz? }\end{array}$ & $5(4,8 \%)$ & $12(11,4 \%)$ & $31(29,5 \%)$ & $33(31,4 \%)$ & $24(22,9 \%)$ \\
\hline $\begin{array}{l}\text { S.7. Yardımcı cihazın tedavideki } \\
\text { etkinliğinden memnun musunuz? }\end{array}$ & $0(0,0 \%)$ & $10(9,5 \%)$ & $17(16,2 \%)$ & $49(46,7 \%)$ & $29(27,6 \%)$ \\
\hline $\begin{array}{l}\text { S.8. Yardimcı cihazın } \\
\text { kullanımından memnun musunuz? }\end{array}$ & $2(1,9 \%)$ & $8(7,6 \%)$ & $26(24,8 \%)$ & $43(41,0 \%)$ & $26(24,8 \%)$ \\
\hline $\begin{array}{l}\text { S.9. Yardımcı cihazın cildinize } \\
\text { uyumundan memnun musunuz } \\
\text { (tahriş açısından)? }\end{array}$ & $3(2,9 \%)$ & $18(17,1 \%)$ & $21(20,0 \%)$ & $37(35,2 \%)$ & $26(24,8 \%)$ \\
\hline $\begin{array}{l}\text { S.10. Yardımcı cihazın } \\
\text { görüntüsünden (estetiğinden) } \\
\text { memnun musunuz? }\end{array}$ & $8(7.6 \%)$ & $12(11,4 \%)$ & $21(20 \%)$ & $40(38,1 \%)$ & $24(22,9 \%)$ \\
\hline
\end{tabular}

Tablo 5. Kullanılan ortez tipi ve yardımcı cihaza göre bireylerin OKMA sorularına verdiği cevapların dağılımı. OKMA: Ortez Kullanım Memnuniyet Anketi.

Tablo 6. Cihaz/Ortez tipi ve OKMA (Toplam) puanına göre fark tablosu.

\begin{tabular}{|c|c|c|c|c|c|}
\hline & Cihaz/ortez tipi & $\mathbf{X} \pm \mathbf{S S}$ & $\mathbf{x 2}$ & $\mathbf{f}$ & $\mathbf{p}$ \\
\hline \multirow{3}{*}{ OKMA (Toplam) } & AFO, DAFO, Ortopedik bot & $59 \pm 47.07$ & \multirow{3}{*}{0.042} & \multirow{3}{*}{2} & \multirow{3}{*}{0.979} \\
\hline & KAFO, UYO & $22 \pm 48.07$ & & & \\
\hline & Diğer & $13 \pm 48.50$ & & & \\
\hline
\end{tabular}



* Kruskal Wallis test p>0,05 OKMA: Ortez Kullanım Memnuniyet Anketi, AFO: Ayak-ayak bileği ortezi, DAFO: Dinamik Ayak Bilek Ortezi,
KAFO: Diz- ayak bileğ -ayak ortezi, UYO: Uzun Yürüme Ortezi.

Bireylerin kullanılan ortez tipi ve yardımcı cihaza göre OKMA sorularına verdiği cevapların \% dağılımları Tablo 5'tedir. Bireylerin kullandıkları ortez tipinin ortez memnuniyet skorlarını etkilemediği bulundu $(\mathrm{p}=0.979)$ (Tablo 6). Bireylerin KMFSS seviyelerinin $(p=0.779)$, tanılarının $(\mathrm{p}=0.236)$ toplam ortez memnuniyet skorunu etkilemediği belirlendi (Tablo 7). Bireyler yardımcı cihaz ve ortezlerini, deformite önleme (\%50), mobilite (\%21), spastisite inhibisyonu $(\% 13,3)$, ayakta durma $(\% 10,5)$ amaciyla kullanıyorlardı. Ayrica yardimc cihaz ve ortezlerin \%81'inin fizyoterapist, \%12'sinin hekim tarafından önerildiği belirlendi. Serabral palsi, spina bifida, musküler distrofi ve diğer kronik engel tanısı olan bireyler arasında ortezlerinden en çok memnun olanların spina bifidalı bireyler olduğu sonra sırasıyla SP, diğer tanılı kronik engelliler ve musküler distrofili bireylerin geldiği belirlendi.

Bireylerin ne kadar süredir ortez kullandığı ile toplam ortez memnuniyet skoru arasında ilişki bulunmazken ( $\mathrm{p}=0.811)$ bulunmazken, günlük ortez kullanım süresi ile toplam ortez memnuniyet skoru arasında bir ilişki olduğu bulundu $(\mathrm{r}=0.242, \mathrm{p}=0.015)$.

\begin{tabular}{|l|c|c|}
\hline \multicolumn{1}{|l|}{ KMFSS (n=64) } & $\begin{array}{c}\text { OKMA(Toplam) } \\
\text { X } \pm \text { SS }\end{array}$ & \multirow{2}{*}{ p } \\
\cline { 1 - 2 } Seviye 1 & $36.42 \pm 10.51$ & \multirow{2}{*}{0.779} \\
\cline { 1 - 2 } Seviye 2 & $38.16 \pm 7.85$ & \\
\cline { 1 - 2 } Seviye 3 & $39.36 \pm 6.43$ & \\
\cline { 1 - 2 } Seviye 4 & $37.77 \pm 8.49$ & \multirow{2}{*}{0.236} \\
\cline { 1 - 2 } Seviye 5 & $36.09 \pm 6.95$ & \\
\cline { 1 - 2 } Tanılar (n=105) & & \\
\cline { 1 - 2 } Serabral palsi & $37.23 \pm 7.47$ & \\
\cline { 1 - 2 } Spina bifida & $40.76 \pm 6.84$ & \\
\cline { 1 - 2 } Musküler distrofi & $34.71 \pm 5.60$ & \\
\cline { 1 - 2 } Diğer & $36.57 \pm 5.87$ &
\end{tabular}

Tablo 7. Çalışmaya katılan bireylerin tanıları ve KMFSS ile OKMA(Toplam) arasındaki ilişkisi

*Kruskal Wallis, KMFSS: Kaba Motor Fonksiyon Sinıflama Sistemi, OKMA:Ortez Kullanım Memnuniyet Anketi.

$\mathrm{Bu}$ çalışmaya katılan bireyler ortez ve yardımcı cihazlarının, en çok giyip çıkarma kolaylığından, cilde uyumundan, görüntüsünden ve konforundan memnun değildi. Ortezlerini kullanmama nedenleri ise ağrı, vurma, tahriş ve cihazın görüntüsü idi. Farklı tanılardaki engelli bireylerin katıldığ 1 bu çalışmada; kronik engelli bireylerin tanıları ile SP'li bireylerin kaba motor fonksiyon seviyeleri ve kullandıkları ortez tipinin ortez memnuniyetini etkilemediği belirlendi. Ayrıca bireylerin günlük ortez kullanım sürelerinin ortez memnuniyetini etkilediği bulunurken, ne kadar zamandır ortez kullandığının ortez memnuniyetini etkilemediği bulundu. Ücret, rahatlık, kontrol ve kozmetik, ideal ortezi tanımlamak için kullanılmış 4 önemli faktör olarak kabul edilir [13]. Ortez kullanan bireylerin önemli bir kısmının günlük hayatta kullandıkları ortezden memnun olmadıkları görülmektedir [6, 12]. Erel ve ark. çocuk hastalarda plastik ayak-ayak bileği ortez görünümünün memnuniyet ve ortezi kabullenme üzerine etkisini inceledikleri çalışmada ortez görünümünün çocuk hastalar için ortezin kabullenilmesi ve ortezden memnuniyet açısından önemli olduğunu bildirmişlerdir [8]. Amosun ve ark. tekerlekli sandalyeden memnuniyetin kullanım kolaylığı, güvenlik ve aktivite katılımı ile bağlantılı olduğunu ve az miktarda da bakım servisleri ile ilişkili olduğunu bildirmişlerdir [14]. Magnusson ve ark., yardimcı cihazdan memnuniyetsizliğin en çok rahatlık, boyutu ve güvenlikten kaynaklandığını söylemişlerdir [15]. Yardımcı cihazların tamiri ve bakımı için bakım servislerine ulaşım oldukça önemlidir. Ayrıca yardımcı cihazın; yolda, evde ve eğimli zeminde yürümeye, merdiven inip çıkmaya, arabaya ve otobüse binip inmeye yardımcı olması nedeniyle ortez memnuniyetini artırdığını bulmuşlardır. Bireylerin yaklaşık 1/3'ünün cihazlarına bağlı olarak ağrı yaşadığı bildirilirken, oldukça az bir kısmı ağrı yaşamadığını ifade etmişlerdir. Yara ya da cilt irritasyonlarının da sıklıkla (\%27) protez ve ortez kullanıcılarında görüldüğünü bildirmişlerdir. Sierra ve ark. yaptıkları çalışmada, bireyler yardımcı cihazlarının rahatlığından, boyutundan ve güvenliğinden memnun olmazken, cihazın dayanıklılığının, tamir ve bakım servislerine ulaşımın oldukça önemli olduğu vurgulanmıştır [15]. Bireylerin yardımcı cihazlarını daha fazla kullandıkları bildirilirken daha fazla ağrı yaşadıkları, basamak ve zeminde yürümede zorlandıkları görülmüştür. Ağrının yardımcı cihazdan memnuniyet düzeyini etkileyen en güçlü faktör olduğu görülmüştür [15]. Ayrıca cihazların kullanılmamasının bir diğer nedeni ise, cihazın zaman içerisinde uygunsuz hale gelmesidir [6].

Magnusson ve ark., Chen ve ark. kullanılan cihazın seviyesi (diz altı, diz üstü vb.) ve ortezin tipi ile ortez memnuniyeti arasında anlamlı ilişsi bildirmişlerdir [5, 15]. Bu sonuçların bizim çalışmamızdan farklı oluşunun nedeninin her iki çalışmadaki bireylerin tanı ve yaş aralığının bu çalışmadaki bireylerden farklı olduğundan kaynaklandığını düşünmekteyiz. Çalışmamıza katılan bireylerin yaş ortalamaları $(12.18 \pm 7.67 \quad$ yıl $)$ bu çalışmalara göre daha düşük idi. Bildiğimiz üzere ortezler bireylerin aktiviteye katılımlarını artırırlar. Böylece okul ve çevreye katılımları, oyun oynamaları daha olanaklı hale gelir.

Chen ve ark., yetersizlik şiddeti ile ortez memnuniyet skoru arasında anlamlı bir ilişki bulmuşlardır [5]. Hafif düzeyde yetersizliği olup bir yıldan az bir süredir bası ürünleri ya da ortez kullanan bireylerin memnuniyetinin en fazla olduğu bildirilmiştir. Hafif düzeyde yetersizliği olan bireylerin orta ve şiddetli yetersizliğe sahip bireylere nazaran memnuniyet düzeyleri önemli ölçüde yüksek bulunmuştur. Çalışmamıza sadece nörolojik etkilenimi olan bireyler dahil edilirken, Chen ve ark., çalışmalarını 
daha heterojen bir grup (ortopedik veya nörolojik etkilenimi olanlar) ile yapmıştır [5].

Dilek ve ark. SP'li çocukların ortez kullanım süresini etkileyen faktörleri inceledikleri çalışmada ebeveynin rehabilitasyon bilgi seviyesi ve SP tipinin önemli olduğunu bildirmiştir [10]. Araştırmamızda ise ebeveynlerin rehabilitasyon bilgi seviyesi sorgulanmamıştır fakat genel eğitim düzeylerinin düşük olduğu görülmektedir. Araştırmamızda SP tipleri değil motor seviyeleri dikkate alınmış ve motor seviyelerinin ortez memnuniyeti ile ilişkili olmadığı saptanmıştır.

Başaran ve ark. nörolojik hastaların alt ekstremite ortezlerinden memnuniyetlerinin orta dereceli olduğunu bildirmiştir [6]. Bazı tanıların (spina bifida, parapleji vb.) karakteristiğindeki duyu kaybı, ortez memnuniyetinin en önemli ölçütlerinden olan ağrıyı kişinin hissetmemesini sağlayarak daha fazla ortez memnuniyetine neden olabileceğini öngörmekteyiz.

Ortez kullanım süresinin ölçümü için daha objektif metodlar tercih eden çalışmalarda mevcuttur [16, 17]. Ortotik cihaza monteli ısıya sensörlü olarak çalışan küçük aletlerin kullanımının, ebeveynlere sorularak öğrenilen ortez kullanım süresinden daha doğru sonuç verdiği bildirilirken, ebeveyne sorularak öğrenilen ortez kullanım süresi ile sensörden alınan ortez kullanım süresi arasında anlamlı fark saptanmıştır [17].

Çalışmamızda bazı limitasyonlar vardır: ortez kullanım süresi, hasta ile iletişim sağlanabiliyorsa hastadan, sağlanamıyorsa ebeveynlerinden öğrenilerek saptanmıştır. Ortez ve yardımcı cihaz kullanım memnuniyetinin ortak bir anketle değerlendirilmesi ayrıca birçok çalışmada ortez ve yardımcı cihazdan memnuniyeti etkileyen önemli faktörlerden biri olarak bildirilen ortez ve yardımcı cihazların tamir, bakım servislerine ulaşım ve ücret bilgisi, bu çalışmada değerlendirilmemiş olup çalışmamızın limitasyonları arasındadır. Bu çalışmada bireylerin yardımcı cihaz ve ortezleri ile ev ve dış ortamdaki aktivitelere katılımı sorgulanmamıştır. Bireylerin aktivite katılımları, kullandıkları yardımcı cihaz ve ortezlerden etkilenebilir ve sonuç olarak ortez ve yardımcı cihaz memnuniyetini etkilenebilir [9]. Ortez ve yardımcı cihaz memnuniyetini değerlendiren Quebecb User Evaluation of Satisfaction with assistive Technology (QUEST 2.0), Client Satisfaction with Device module of the Orthotics and Prosthetic Users'(CSD-OPUS) gibi test bataryaları da mevcuttur [1]. Bu testlerin Türkçe geçerlilik güvenilirliği yapılmamış olduğundan literatüre dayalı olarak oluşturduğumuz anket kullanılmıştır.

\section{Sonuç}

Sonuç olarak, kronik engelli bireylerde ortez/yardımcı cihaz günlük kullanım süresi arttıkça kullanım memnuniyetinin arttığı görüldü. Yardımcı cihaz/ortez tipinin ortez kullanma memnuniyeti ile ilşkili olmadığ gözlemlendi. Ayrıca serebral palsili, spina bifida, musküler distrofi ve diğer tanı gruplarının ortez memnuniyetlerinin benzer olduğu görüldü. Yardımcı cihazların ve ortezlerin çocuğa, ailesine ve sosyal çevresine nasıl katkı sağlayacağı konusunda klinisyenlere rehberlik görevi düşmektedir. Yardımcı cihaz/ortezlerin uygun kullanımı, düzenli takip, hasta ve ebeveynlerin eğitimi ve kullanıcıların bilgilendirilmesi düşük düzeyde çıkan memnuniyeti arttırabilir. Orteze uyum konusunda geçerlilik ve güvenilirliği yapılmış ve kültürel adaptasyonu sağlanmış anketler ile birlikte daha kapsamlı çalışmalara ihtiyaç duyulmaktadır.

\section{Referanslar:}

1. Bettoni E, G Ferriero, et al. A systematic review of questionnaires to assess patient satisfaction with limb orthoses, Prosthetics and Orthotics International, 2016, 40(2), 158-69.

2. Karaduman A, Yilmaz ÖT., Ortopedik Rehabilitasyon Pediatrik Rehabilitasyon; Pelikan Yayınevi: Ankara, Turkiye, 2016; pp 1079. 138.

3. Demers L, M Monette, et al. Reliability, validity, and applicability of the Quebec User Evaluation of Satisfaction with assistive Technology (QUEST 2.0) for adults with multiple sclerosis. Disability and Rehabilitation, 2002, 24(1-3), 21-30.

4. Copley J, J Ziviani. Barriers to the use of assistive technology for children with multiple disabilities, Occupationl Therapy International, 2004, 11(4), 229-43.

5. Chen C-L, Y-L Teng,, et al. User satisfaction with orthotic devices and service in Taiwan, PloS One, 2014, 9(10), e110661.

6. Basaran S, IC Benlidayi, et al. Actual use and satisfaction of lower extremity orthoses in neurological disorders, Turkish Journal Physical Medicine and Rehabilitation, 2016, 62(2),143-7.

7. Rackauskaite, Gija, et al. Impact of child and family characteristics on cerebral palsy treatment, Develoğmental Medicine and Child Neurology, 2015, 57(10), 948-954.

8. Erel S, IE Simsek, et al. The effect of plastic foot-ankle orthosis appearance in childhood on satisfaction and orthosis acceptance, Turkish Journal of Physical Medicine and Rehabilitation, 2007, 18(3), 195-200.

9. Lee S-H. Users' satisfaction with assistive devices in South Korea, Journal of Physical Therapy Science, 2014,26(4), 509-12.

10. Dilek B, G Gozde, Y Yakut. An investigation of the duration of ankle foot orthosis'daily usage in children withcerebral palsy: a pilot study, Journal of Exercise Therapy and Rehabilitation, 2015, 2(2), 47-52.

11. Peaco A, E Halsne, BJ Hafner. Assessing satisfaction with orthotic devices and services: a systematic literature review, Journal of Prosthetics and Orthotics, 2011, 23(2), 95-105.

12. Holtkamp F, E Wouters, et al. Use of and satisfaction with ankle foot orthoses, Clinical Research on Foot and Ankle, 2015, 3(1), 1000167.

13. Hovorka C, M Geil, M Lusardi. Orthotics and Prosthetics in Rehabilitation. 2nd edn. Oxford, Butterworth-Heinemann, 2007, pp 135-6.

14. Amosun S, A Ndosi, H Buchanan. Locally manufactured wheelchairs in Tanzania-are users satisfied, African Health Sciences, 2016, 16(4), 1174-81

15. Magnusson L, G Ahlström. Patients' Satisfaction with Lower-limb Prosthetic and Orthotic Devices and Service delivery in Sierra Leone and Malawi, BMC Health Services Research, 2017, 17(1), 102.

16. Bus SA, R Waaijman, F Nollet. New monitoring technology to objectively assess adherence to prescribed footwear and assistive devices during ambulatory activity, Archives of Physical Medicine and Rehabilitation, 2012, 93(11), 2075-9.

17. Maas JC, AJ Dallmeijer, BY Oudshoorn. Measuring wearing time of knee-ankle-foot orthoses in children with cerebral palsy: comparison of parent-report and objective measurement, Disability Rehabilitation, 2018, 40(4), 398-403.

http://edergi.cbu.edu.tr/ojs/index.php/cbusbed isimli yazarın CBU-SBED başlıklı eseri bu Creative Commons Alıntı-Gayriticari4.0 Uluslararası Lisansı ile lisanslanmıştır.

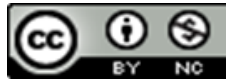

